\title{
LEVEL OF PATIENTS' SATISFACTION WITH THE DENTAL CARE PROVIDED AT PRIVATE DENTAL HOSPITAL, PESHAWAR
}

\author{
Yasir Khattak', Ruqayya Sana', Shakeel-Ur-Rehman'1, Ammara Sami', Gulandana Alam Khan', \\ Michelle Khan ${ }^{1}$
}

\section{Sardar Begum Dental College}

\section{ABSTRACT}

\section{OBJECTIVE}

Quality is a major concern of health care authorities all over the world. Patient satisfaction regarding the dental treatment they receive is essential for the improvement of oral health service and practice. The aim of this study is to evaluate the levels of patient satisfaction regarding quality of dental care provided at Sardar Begum Dental Hospital.

\section{METHODS}

A random sampling technique based over one-month period; June $5^{\text {th }}$ - July $5^{\text {th }} 2016$ was used. Comprising of interviewer-administered questionnaires with a five point Likert scale (strongly agree, agree, uncertain, disagree, strongly disagree) to assess the level of patients' satisfaction with the dental services provided at the Sardar Begum Dental Hospital.

\section{RESULTS}

A total of 360 patients participated that has received and/or was still receiving treatment at Sardar Begum Dental Hospital with a response rate of $73 \%$. The overall estimate of factors related to satisfaction showed a mean percentage of $74.8 \%$ for the 4 disciplines of satisfaction displaying a high level of satisfaction.

\section{CONCLUSION}

Majority of patients receiving treatment at Sardar Begum Dental Hospital were satisfied with dentist-patient interaction, administrative efficiency, technical competency and hospital environment.

KEY WORDS: Patient's Satisfaction. Dental Hospitals.

\section{INTRODUCTION}

Patients seek dental treatment to relieve pain, provide regular oral health examinations, improve aesthetics and provide full mouth rehabilitation for normal function (1). Selections of dental hospitals are usually based on accessibility, affordability and professional competence of dentists

Correspondence:

Dr. Shakeel-Ur-Rehman

Sardar Begum Dental College

Contact: 0300-0910080

Email: shak.khattak@gmail.com

https://doi.org/10.37762/jgmds.3-2.36 and the dental staff. Patient satisfaction regarding dental treatment is vital for continuous improvement of the service delivery and outcome (1). Quality is a major concern of health care authorities all over the world. Patient satisfaction regarding the dental treatment they receive is essential for the improvement of oral health service and practice (2). Complaints made by patients might have unwelcome consequences in terms of people's perception regarding the hospital providing the dental care (2). In the period of clinical governance, it is of utmost importance that patients' concerns are dealt appropriately. Several studies from around the world have reported about patient satisfaction following dental 
treatment from dental training centers. Patient satisfaction regarding the dental treatment provided is a multidimensional concept and is critical fororal health service (2).

A research was carried out into the levels of patient satisfaction receiving dental treatment at Sardar Begum Dental Hospital. On one hand such research would help in incorporating patients opinion regarding their expectations from the services because sometimes what patient wants differ from what the provider thinks is best for them. On other hand, it would benefit the hospital by providing a holistic view of factors affecting the patients' satisfaction. Use of interviewer administered questionnaires in attempt to quantify the level of satisfaction with dental services provided at Sardar Begum Dental Hospital. The aim of this study was to conduct a research regarding levels of satisfaction among patients to determine the factors affecting patients' satisfaction when receiving the treatment and to come up with recommendations and share them with the administration in order to eliminate any source of dissatisfaction(2).

\section{METHODOLOGY}

The patients that have received and/or were still receiving treatment at Sardar Begum Dental Hospital were the target population whose perceptions were collected in the form of a patient satisfaction questionnaire. A cross-sectional study design was used from June $5^{\text {th }}-J$ July $5^{\text {th }} 2016$. Data was collected through random sampling technique. Interviewer administered questionnaires were drafted in English. In addition to the socio demographic characteristics (name, age, gender, education level, and socioeconomic status) it comprised of four main disciplines of satisfaction .i.e. dentist-patient interaction (8 items), administrative efficiency(5 items), technical competency (5 items) and hospital environment (2 items)(2). A suggestion box was also placed for patients' opinions regarding improvement of our services. The questionnaire also comprised of five point Likert scale (strongly agree, agree, uncertain, disagree, strongly disagree) to assess the level of patients' satisfaction with the dental services provided at the Sardar Begum Dental Hospital (1).

\section{RESULTS}

A total of 360 patients participated out of 493 patients that received or were still receiving treatment at Sardar Begum Dental Hospital. The targeted population was equally distributed among the 6 major departments of Sardar Begum Dental Hospital .i.e. Operative and Endodontic department, Orthodontic department, Periodontology department, Oral and Maxillofacial Surgery department, Paedodontics department and Prosthodontics department.

Patient satisfaction was measured according to four disciplines; dentist-patient interaction, administrative efficiency, technical competency and hospital environment(2). During calculations strongly disagree and disagree were counted as one unit while strongly agree and agree were counted as one. Each section was measured in different departments individually and then an overall mean score was concluded. Table 1 shows the patient satisfaction disciplines measured in Paedodontic, Orthodontic, Prosthodontic, Operative, Oral-surgeryand periodontology departments. It shows that more than two-third of the patients were satisfied with patient-dentist interaction, technical competency and the hospital environment. However, about $67 \%$ reported that treatment cost was high.

In Orthodontic department it shows a major amount of patients satisfied with the treatment. In Prosthodontics and Operative and Endodontic department a large amount of patients are satisfied with the four disciplines of satisfaction but on other hand about more than two-third patients did complain about the prolong waiting time to receive the treatment. In Oral and Maxillofacial Surgery 
and Periodontology department about 98\% reported that they had other problems which were not treated.

Overall ranking of factors related to satisfaction was done by calculating the mean percentage of agreement regarding the different disciplines of satisfaction among the different departments (Table 2 and Fig 1). The mean percentage of agreement for the four disciplines was $74.8 \%$ denoting a high level of satisfaction.

Table1: Patient Satisfaction Disciplines Measured In Different Departments.

\begin{tabular}{|c|c|c|c|c|c|c|c|c|c|c|c|c|c|c|c|c|c|c|}
\hline \multirow{2}{*}{ Item } & \multicolumn{3}{|c|}{ Peads } & \multicolumn{3}{|c|}{ Ortho } & \multicolumn{3}{|c|}{ Prosth } & \multicolumn{3}{|c|}{ Operative } & \multicolumn{3}{|c|}{ Surgery } & \multicolumn{3}{|c|}{ Perio } \\
\hline & A & $\mathbf{U}$ & D & A & $\mathbf{U}$ & D & A & $\mathbf{U}$ & D & A & $\mathbf{U}$ & D & A & $\mathbf{U}$ & D & A & $\mathbf{U}$ & D \\
\hline \multicolumn{19}{|c|}{ Patient's satisfaction on patient - dentist interaction: } \\
\hline 1. Dentist was friendly with me & 53 & 00 & 07 & 59 & 1 & 0 & 58 & 0 & 2 & 60 & 0 & 0 & 60 & 0 & 0 & 60 & 0 & 0 \\
\hline $\begin{array}{l}\text { 2. Dentist explained the procedures } \\
\text { before start of the treatment }\end{array}$ & 60 & 00 & 00 & 55 & 1 & 4 & 58 & 0 & 2 & 58 & 2 & 0 & 59 & 0 & 1 & 56 & 2 & 2 \\
\hline $\begin{array}{l}\text { 3. Dental staff was concentrating on } \\
\text { their work }\end{array}$ & 60 & 00 & 00 & 56 & 2 & 2 & 48 & 10 & 2 & 55 & 5 & 0 & 52 & 6 & 2 & 49 & 5 & 6 \\
\hline $\begin{array}{l}\text { 4. Dental staff did not talk with each } \\
\text { other while providing the treatment }\end{array}$ & 60 & 00 & 00 & 41 & 9 & 10 & 44 & 14 & 2 & 56 & 1 & 3 & 51 & 6 & 3 & 50 & 0 & 10 \\
\hline $\begin{array}{l}\text { 5. Dentist gave me advices after } \\
\text { treatment }\end{array}$ & 60 & 00 & 00 & 56 & 2 & 2 & 51 & 09 & 0 & 60 & 0 & 0 & 59 & 0 & 1 & 60 & 0 & 0 \\
\hline $\begin{array}{l}\text { 6. Dentist did not criticize my oral } \\
\text { condition }\end{array}$ & 55 & 00 & 05 & 53 & 4 & 3 & 44 & 16 & 0 & 60 & 0 & 0 & 60 & 0 & 0 & 51 & 0 & 9 \\
\hline 7. The treatment was not rushed & 60 & 00 & 00 & 57 & 3 & 0 & 56 & 04 & 0 & 57 & 3 & 0 & 58 & 2 & 0 & 45 & 0 & 15 \\
\hline $\begin{array}{l}\text { 8. I was not involved in the important } \\
\text { decisions about my treatment }\end{array}$ & 60 & 00 & 00 & 56 & 0 & 4 & 56 & 03 & 1 & 33 & 20 & 7 & 14 & 7 & 39 & 60 & 0 & 0 \\
\hline \multicolumn{19}{|c|}{ Patient's satisfaction with technical competency: } \\
\hline $\begin{array}{l}\text { 9. Cross infection control measures } \\
\text { were taken }\end{array}$ & 60 & 00 & 00 & 60 & 0 & 0 & 57 & 03 & 0 & 60 & 0 & 0 & 59 & 1 & 0 & 60 & 0 & 0 \\
\hline 10. Treatment offered was not painful & 00 & 00 & 00 & 40 & 0 & 20 & 48 & 09 & 3 & 42 & J & 3 & 20 & 2 & 38 & 60 & 0 & 0 \\
\hline $\begin{array}{l}\text { 11. Dental instruments used were } \\
\text { sterilized }\end{array}$ & 60 & 00 & 00 & 60 & 0 & 0 & 51 & 09 & 0 & 60 & 0 & 0 & 58 & 0 & 2 & 60 & 0 & 0 \\
\hline $\begin{array}{l}\text { 12. Options of more than } 1 \text { form of } \\
\text { treatment was given to choose from }\end{array}$ & 00 & 60 & 00 & 60 & 0 & 0 & 60 & 00 & 0 & 20 & 10 & 30 & 56 & 1 & 3 & 40 & 0 & 20 \\
\hline $\begin{array}{l}\text { 13. There were other dental problems } \\
\text { I had that were not treated }\end{array}$ & 00 & 00 & 00 & 60 & 0 & 0 & 03 & 03 & 54 & 4 & 12 & 44 & 01 & 0 & 59 & 60 & 0 & 0 \\
\hline \multicolumn{19}{|c|}{ Patient's satisfaction with administrative efficiency: } \\
\hline $\begin{array}{l}\text { 14. Working hours of the hospital } \\
\text { were suitable }\end{array}$ & 60 & 00 & 00 & 50 & 3 & 7 & 44 & 11 & 5 & 55 & 5 & 0 & 59 & 0 & 1 & 60 & 0 & 0 \\
\hline $\begin{array}{l}\text { 15. Travel to the hospital was } \\
\text { convenient }\end{array}$ & 60 & 00 & 00 & 46 & 4 & 10 & 40 & 07 & 13 & 56 & 2 & 2 & 59 & 0 & 1 & 60 & 0 & 0 \\
\hline $\begin{array}{l}\text { 16. Short waiting time to get the } \\
\text { treatment }\end{array}$ & 27 & 00 & 33 & 44 & 0 & 16 & 12 & 08 & 40 & 5 & 4 & 51 & 11 & 6 & 43 & 25 & 0 & 35 \\
\hline 17. The treatment cost was affordable & 20 & 00 & 40 & 60 & 0 & 0 & 20 & 00 & 40 & 30 & 6 & 24 & 44 & 6 & 10 & 60 & 0 & 0 \\
\hline 18. Privacy of treatment was insured & 60 & 00 & 0 & 60 & 0 & 0 & 48 & 07 & 5 & 60 & 0 & 0 & 52 & 2 & 6 & 60 & 0 & 0 \\
\hline \multicolumn{19}{|c|}{ Patient's satisfaction with hospital environment: } \\
\hline 19. The hospital is clean & 50 & 00 & 10 & 40 & 0 & 20 & 54 & 05 & 1 & 59 & 1 & 0 & 48 & 1 & 11 & 50 & 5 & 5 \\
\hline 20. The waiting area is comfortable & 50 & 00 & 01 & 45 & 0 & 15 & 34 & 20 & 6 & 42 & 4 & 14 & 22 & 8 & 30 & 12 & 8 & 4 \\
\hline
\end{tabular}




\section{DISCUSSION}

The level of patient satisfaction was conducted from June 5th to July 5th 2016. The patients that have received or were still receiving treatment at Sardar Begum Dental Hospital were the target population. Patient satisfaction questionnaires were used to assess the levels of patient satisfaction with the treatment. A response rate of $73 \%$ was achieved in which majority of the patients attending the hospital were adults or middle aged. Conclusion of this study will help determine the factors affecting patients' satisfaction when receiving the treatment and aid in eliminating any source of dissatisfaction. Table 2 and Fig (1) shows the overall average mean score for the four disciplines of satisfaction. A mean percentage of $74.8 \%$ was calculated which denotes a high level of satisfaction.

Around $89 \%$ reported that they were satisfied with patient- dentist interaction and the remaining population showed disagreement as they were not included in the important decisions of their treatment.

Concerning other disciplines, $75 \%$ concluded that administrative efficiency was satisfactory but $25 \%$ expressed dissatisfaction due to prolong waiting and treatment time. This can be related to the fact that many treatments are lengthy and require more time. $70 \%$ stated that hospital environment was clean and comfortable. The least satisfaction (64.5\%) was from technical competency as the patient stated that many treatment options were not given and there were other treatment problems that were not solved before starting the treatment. Patients were also enquired about their pre and post treatment oral hygiene status which showed an average score of $82 \%$, denoting a high level of satisfaction regarding their oral health after the treatment.

This study will act as a guide to come up with recommendations and share them with the administration in order to eliminate any source of dissatisfaction to improve the service delivery and outcome.

Table 2: overall satisfaction for the four disciplines

Item agree uncertain disagree

Patient's satisfaction on patient - dentist interaction:
1. Dentist was friendly with me
$350(97 \%)$
$1(0.2 \%) \quad 9(2.5 \%)$

2. Dentist explained the procedures before start of the treatment $346(96 \%) \quad 5(1.3 \%) \quad 9(2.5 \%)$

3. Dental staff was concentrating on their work $\quad 320(88 \%) \quad 28(7.7 \%) \quad 12(3.3 \%)$

4. Dental staff did not talk with each other while providing the $302(83 \%) \quad 30(8.3 \%) \quad 28(7.7 \%)$ treatment

5. Dentist gave me advices after treatment

$346(96 \%) \quad 11(3.0 \%) \quad 3(0.8 \%)$

6. Dentist did not criticize my oral condition

$323(89 \%) \quad 20(5.5 \%) 17(4.7 \%)$

7. The treatment was not rushed

$333(92 \%) \quad 12(3.3 \%) \quad 15(4.1 \%)$

8. I was not involved in the important decisions about my treatment $\quad 279(77 \%) \quad 30(8.3 \%)$ $51(14.1 \%)$

\section{Patient's satisfaction with technical competency:}

9. Cross infection control measures were taken

10. Treatment offered was not painful

$\begin{array}{ccc}356(98 \%) & 4(1.1 \%) & 0(0 \%) \\ 210(58 \%) & 26(7.2 \%) & 124(34 \%)\end{array}$


11. Dental instruments used were sterilized

12. Options of more than 1 form of treatment was given to $236(65 \%)$

$77(21 \%)$

$47(13 \%)$ choose from

13. There were other dental problems I had that were not treated $68(18.8 \%) \quad 79(22 \%) 213(59 \%)$ Patient's satisfaction with administrative efficiency:
14. Working hours of the hospital were suitable
$328(91 \%)$
$19(5.2 \%)$
$13(3.6 \%)$
15. Travel to the hospital was convenient
$321(89 \%)$
$31(8.6 \%)$
$8(2.2 \%)$
16. Short waiting time to get the treatment
$124(34 \%) \quad 18(5 \%) \quad 218(60 \%)$
17. The treatment cost was affordable $234(65 \%)$
$18(5 \%)$
$108(30 \%)$
18. Privacy of treatment was insured

Patient's satisfaction with hospital environment:
19. The hospital is clean
$301(84 \%)$
$12(3.3 \%)$
$47(13 \%)$
20. The waiting area is comfortable
$205(57 \%)$
$20(5.5 \%)$
$135(37 \%)$

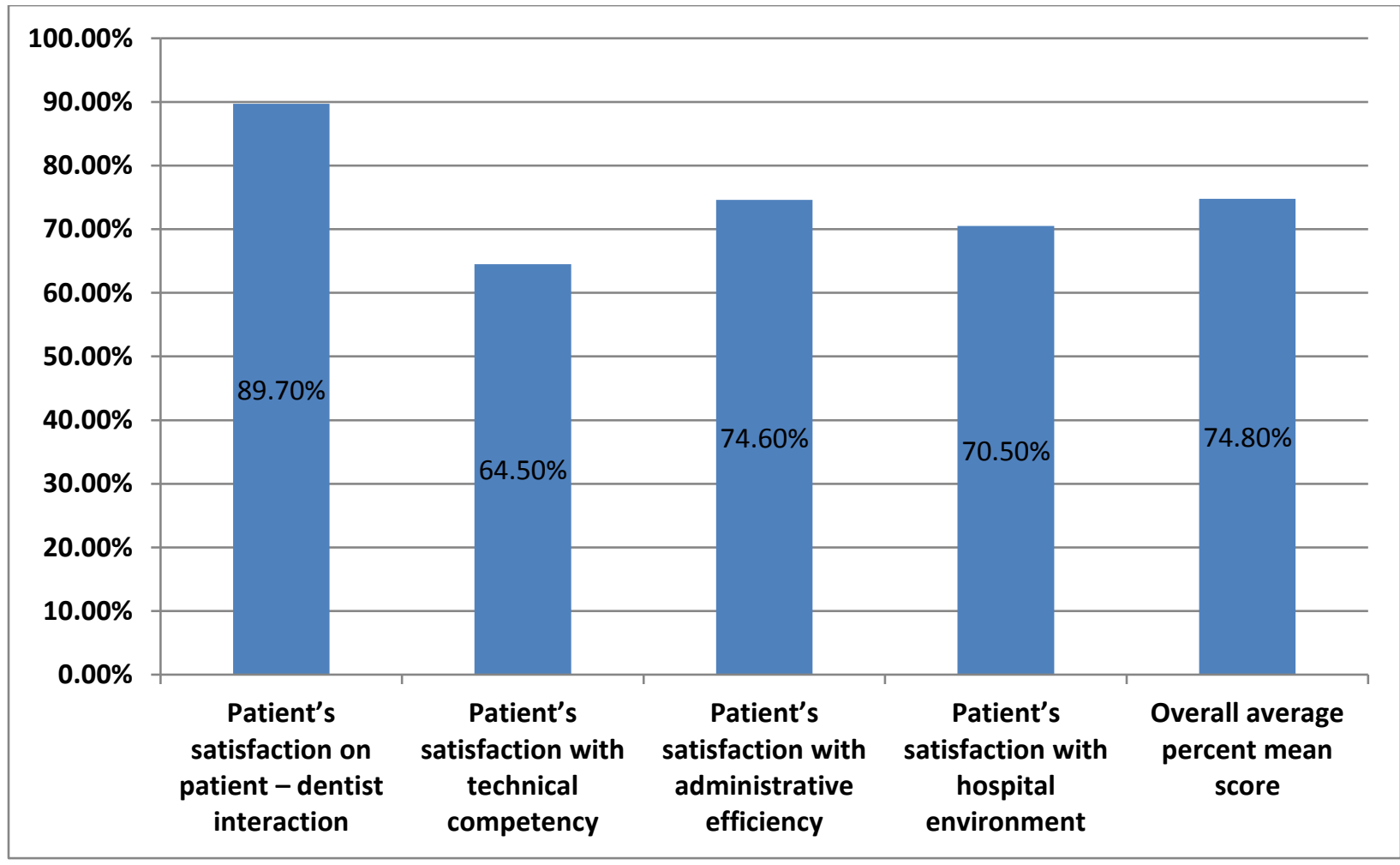

Fig1: overall mean percentage of the four disciplines of satisfaction.

\section{CONCLUSION}

The results indicated that the majority of patients were satisfied with the patient-dentist interaction, technical competency, administrative efficiency and hospital environment at Sardar Begum Dental Hospital. 


\section{RECOMMENDATION}

Patient satisfaction regarding the dental treatment they receive is essential for the development of oral health service and measures should be taken to reduce and eliminate any source of dissatisfaction.

\section{REFERENCES}

1. Syed Rashid Habib, SundarRamalingam, Abdullah Al Belad, Abdullah Al Habib, Patients' satisfaction with the dental care provided by the dental students, King Saud University, Riyadh, Kingdom of Saudi Arabia.

2. Mohamed SaadMahrous, PhD and Tamer Hifnawy, MD.Dr.PH, Clinical Study of Patient satisfaction from dental services provided by the College of Dentistry, Taibah University, Saudi Arabia.

3. Othman L, Jaafar N. A survey of customer satisfaction with the school dental service among 16 year old school children in the District of Tawau, Sabah. Kuala Lumpur, Malaysia: Oral Health Division Ministry of Health and University of Malaya; 2004.

4. Noormi Othman, Ishak Abdul-Razak. Satisfaction with school dental service provided by mobile dental squads. Asia Pac J Public Health 2010.

5. Stewart JF \& Spencer AJ.Dental satisfaction survey. Dental statistics and Research unit 2005

6. Mike Busby BDS (Hons) U Lond.LDSRCS Eng. DGDP.FDRSRCS Ed. measuring success in dental practice using patient feedback.

7. Bhoopati, Vinodh, 'Determining the level of Patient satisfaction in a dental hygiene setting'. (2005).

LICENSE: JGMDS publishes its articles under a Creative Commons Attribution Non-Commercial Share-Alike license (CC-BY-NC-SA 4.0). COPYRIGHTS: Authors retain the rights without any restrictions to freely download, print, share and disseminate the article for any lawful purpose. It includes scholarly networks such as Research Gate, Google Scholar, LinkedIn, Academia.edu, Twitter, and other academic or professional networking sites. 